\title{
Metformin Alleviates Radiation-Induced Skin Fibrosis via the Downregulation of FOXO3
}

\author{
Jin-Mo Kim ${ }^{\mathrm{a}}$ Hyun Yoo Jee-Youn Kim ${ }^{\mathrm{a}}$ Sang Ho Oh ${ }^{\mathrm{b}}$ Jeong Wook Kang \\ Byung Rok Yoo ${ }^{a}$ Song Yee Han ${ }^{a}$ Cha Soon Kim ${ }^{c}$ Won Hoon Choi ${ }^{a}$ \\ Eun-Jung Lee Hyeong Ju Byeon $^{a}$ Won Jai Lee ${ }^{d}$ Yun-Sil Lee ${ }^{e}$ Jaeho Cho \\ aDepartment of Radiation Oncology, Yonsei University Health System, Seoul, bepartment of \\ Dermatology, Yonsei University Health System, Seoul, 'Radiation Epidemiology Team, Radiation Health \\ Institute KHNP, Seongnam-si, 'Department of Plastic Surgery, Yonsei University Health System, Seoul, \\ eGraduate School of Pharmaceutical Sciences, Ewha Womans University, Seoul, South Korea
}

\section{Key Words}

Radiation-induced skin fibrosis • Metformin • FOXO3 • PIK3r1

\begin{abstract}
Background/Aims: Radiation-induced skin fibrosis is a common side effect of clinical radiotherapy. Our previous next-generation sequencing (NGS) study demonstrated the reduced expression of the regulatory $\alpha$ subunit of phosphatidylinositol 3-kinase (PIK3r1) in irradiated murine skin. Metformin has been reported to target the PIK3-FOXO3 pathway. In this study, we investigated the effects of metformin on radiation-induced skin fibrosis. Methods: Metformin was orally administered to irradiated mice. Skin fibrosis was analyzed by staining with $\mathrm{H} \& \mathrm{E}$ and Masson's trichrome stain. The levels of cytokines and chemokines associated with fibrosis were analyzed by immunohistochemistry and quantitative RT-PCR. The roles of PIK3rl and FOXO3 in radiation-induced skin fibrosis were studied by overexpressing PIK3rl and transfecting FOXO3 siRNA in NIH3T3 cells and mouse-derived dermal fibroblasts (MDF). Results: The oral administration of metformin significantly reduced radiation-induced skin thickening and collagen accumulation and significantly reduced the radiation-induced expression of FOXO3 in murine skin. Additionally, the overexpression of PIK3r1 reduced the radiation-induced expression of $\mathrm{FOXO3}$, while $\mathrm{FOXO} 3$ silencing decreased the radiationinduced expression of TGF $\beta$ in vitro. Conclusions: The results indicated that metformin suppresses radiation-induced skin injuries by modulating the expression of FOXO3 through PIK3r1. Collectively, the data obtained in this study suggested that metformin could be a potent therapeutic agent for alleviating radiation-induced skin fibrosis.
\end{abstract}




\section{Cellular Physiology Cell Physiol Biochem 2018;48:959-970 \\ \begin{tabular}{l|l} 
DOI: 10.1159/000491964 2018 & $\begin{array}{l}\text { O } 2018 \text { The Author(s). Published by S. Karger AG, Basel } \\
\text { www.karger.com/cpb }\end{array}$
\end{tabular} \\ Kim et al.: Metformin Regulates Radiation-Induced Skin Fibrosis}

\section{Introduction}

Radiation therapy (RT) is widely used to treat various types of cancers; however, it can induce toxicity to the surrounding normal tissues [1-4]. Since skin is often irradiated during $\mathrm{RT}$, radiation may lead to inadvertent and deleterious skin reactions. Although the recent use of hypofractionated radiotherapy, including stereotactic body radiotherapy (SBRT), produces less damaging effects on the skin, some reports on the use of SBRT for early lung cancer and breast cancer indicate increased skin toxicities [3, 4]. Radiation-induced skin injuries include acute and chronic skin injuries, comprising of morphological and functional changes. Acute skin injury is characterized by erythema, dry and moist desquamation, and hair loss, while chronic skin injury is characterized by fibrosis and necrosis [5]. Unfortunately, apart from conservative management, only few preventive measures or effective remedies are presently available for the treatment of radiation-induced skin damage [6, 7].

Advances in cellular and molecular biology techniques have made it possible to elucidate the mechanisms of fibrosis, while offering new theoretical treatment strategies. However, the cause behind the continued fibroblast activation in chronic fibrosis remains unknown [8, 9]. Over the years, fibrosis had been considered to be an irreversible accumulation of dead scar tissues. Recent reports have revealed that it is a dynamic process, consisting of constant "remodeling" and the long-term activation of fibroblasts. Various factors contributing to fibrosis have been identified, and many antioxidant studies have shown that these agents are effective for radiation-induced fibrosis (RIF) $[10,11]$. Despite these studies, few treatments for RIF are in use.

Metformin, which belongs to the biguanide family of anti-diabetic drugs, is a primary drug for the treatment for type 2 diabetes. Metformin has been shown to inhibit the TGF $\beta$ signaling pathway during the differentiation of myofibroblasts and cardiac fibrosis [12, 13]. Treatment with metformin was also shown to reduce the accumulation of collagen in a bleomycin-induced pulmonary lung fibrosis [14], while attenuating pulmonary fibrosis induced by radiation in a mouse model [15]. However, the specific molecular mechanism by which metformin suppresses the radiation-induced skin fibrosis to be understood.

A complex signaling network involving phosphatidyl inositol 3-kinase (PI3K) regulates the proliferation and differentiation of skin cells $[16,17]$. PI3K is an obligate heterodimer comprising of a regulatory subunit (p85 $\alpha$, PIK3r1) and a catalytic subunit (p110, PIK3ca) that is activated by receptor tyrosine kinases [18]. The components functioning downstream of the PI3K/AKT signaling cascade include the forkhead box-O (FOXO) family of transcription factors [19] and members of the p53 pathway [20], which regulate cell survival, apoptosis, and progression through the cell cycle [21, 22]. FOXO plays an important role in the transdifferentiation of hematopoietic stem cells (HSCs) in hepatic fibrosis [23] and renal fibrosis [24], and has recently been shown by siRNA-mediated silencing [25] to reduce the expression of the transforming growth factor $\beta$ (TGF $\beta$ ). In addition, p53 was found to transactivate FOXO3 in fibroblasts by binding to the second intron of FOXO3 [26].

In this study, we investigated the effect of metformin and the mechanism by which metformin regulates the expression of FOXO3 in radiation-induced skin injury. Understanding and regulating the expression of FOXO3 might be critical for developing an effective medical countermeasure against radiation-induced skin fibrosis.

\section{Materials and Methods}

\section{Cell culture}

Primary mouse dermal fibroblasts, MDF and a mouse fibroblast cell line, NIH3T3 were grown in Dulbecco's Modified Eagle Medium (DMEM) supplemented with 10\% fetal bovine serum (FBS), 100 units/ $\mathrm{mL}$ penicillin, and $100 \mathrm{\mu g} / \mathrm{mL}$ streptomycin at $37^{\circ} \mathrm{C}$ in a humidified $5 \%\left(\mathrm{v} / \mathrm{v}\right.$ ) CO${ }_{2}$ atmosphere. $1.0 \times 10^{6}$ cells were seeded at about $80 \%$ on $60 \mathrm{~mm}$ dish and were incubated with serum-free medium for 24 hours and irradiated. 


\section{Cellular Physiology Cell Physiol Biochem 2018;48:959-970 \begin{tabular}{l|l} 
and Biochemistry Published onIne: July 23, 2018 & $\begin{array}{l}\text { D } 2018 \text { The Author(s). Published by S. Karger AG, Basel } \\
\text { www.karger.com/cpb }\end{array}$
\end{tabular} Kim et al.: Metformin Regulates Radiation-Induced Skin Fibrosis}

Western blot analysis

Cells were lysed with radioimmunoprecipitation assay (RIPA) buffer (50 mM Tris-HCl, pH 7.4, 1\% Nonidet P-40, $0.25 \%$ sodium deoxycholate, $150 \mathrm{mM} \mathrm{NaCl}$, and $1 \mathrm{mM} \mathrm{Na}_{3} \mathrm{VO}_{4}$ ) containing protease inhibitors (2 mM phenylmethylsulfonyl fluoride, $100 \mu \mathrm{g} / \mathrm{ml}$ leupeptin, $10 \mu \mathrm{g} / \mathrm{ml}$ pepstatin, $1 \mu \mathrm{g} / \mathrm{ml}$ aprotinin, and 2 mM EDTA) and phosphatase inhibitor cocktail (GenDEPOT, Baker, TX). After the extract was incubated for 20 minutes at $4^{\circ} \mathrm{C}$, the lysates were centrifuged at $13,000 \mathrm{rpm}$ for 20 minutes at $4^{\circ} \mathrm{C}$, and the supernatants were collected for Western blotting. The protein concentration was measured using a BCA protein kit (Bio-rad USA). The lysates were loaded onto sodium dodecyl sulfate-polyacrylamide gels (SDS-PAGEs) for electrophoresis. They were subsequently transferred onto polyvinylidene fluoride membranes (Millipore, Bedford, MA, USA). The membranes were incubated with 5\% skim milk for 1 hour at room temperature and were probed with primary antibody, followed by incubation with horseradish peroxidase-coupled secondary antibody. Proteins were detected with ECL Plus Western blotting detection reagents (Amersham Biosciences Co., Piscataway, NJ, USA).

\section{Transfection}

Transient transfections were performed with Efectene (Qiagen; Santa Clara, CA, USA) according to the manufacturer's protocol. In brief, $5.0 \times 10^{5}$ cells were placed in a $60 \mathrm{~mm}$ dish the day before the transfection and were grown to approximately $70 \%$ confluence. Then, cell were transfected with $1 \mu$ g plasmid DNA for PIK3r1 or silencing RNA (si-RNA) $10 \mathrm{nM}$ for FOXO3 or p53 gene (cell signaling). The next day, the transfected cells were untreated or treated with radiation (10 Gy) for 24 hours. After 24 hours, cells were harvested for protein extraction, real-time qPCR or further analysis. All experiment were performed in triplicate, and representative results were reported.

\section{Quantitative real-time polymerase chain reaction (PCR)}

Total RNA was isolated from cells with Trizol Reagent (Invitrogen, Carlsbad, CA, USA) according to the manufacturer'sinstructions, and the QuantifectReverse Transcription Kit (Qiagen, Hilden, Germany) wasused to synthesize cDNA. Real-time PCR reactions included SYBR Premix Ex Taq (Takara), primers, RNase-free $\mathrm{H}_{2} \mathrm{O}$, and cDNA in a final reaction volume of $20 \mu \mathrm{l}$. The real-time PCR cycling conditions were $95^{\circ} \mathrm{C}$ for 10 minutes, followed by 50 cycles of $95^{\circ} \mathrm{C}$ for $20 \mathrm{sec}, 55^{\circ} \mathrm{C}$ for $30 \mathrm{sec}$, and $72^{\circ} \mathrm{C}$ for $20 \mathrm{sec}$. The sequences of the mouse primers were as follows: $I L$ - $1 b$ (FW $5^{\prime}$-TGGTGTGTGACGTTCCCATT-3'; RW 5'-CAGCACGAGGCTTTTTTGTTG-3'), IL-6 (FW 5'-ACAAGTCGGAGGCTTAATTACACAT-3'; RW 5'-TTGCCATTGCACAACTCTTTTC-3'), IL-8 (FW 5'-CTCCAGCCACACTCCAACAGA-3'; RW 5'-CACCTAACACACCCACGAT-3'), TGF 3 (FW 5'-GCAACATGTGGAACTCTACCAGAA-3; ${ }^{\prime}$ RW 5'-GACGTCAAAAGACAGCCACTC-3'), CCL2 (FW 5'-GCTGACCCCAAGAAGGAATG-3'; RW 5'-GTGCTTGAGGTGGTTGTGGA-3'), CCL4 (FW 5'-CCAGGGTTCTCAGCACCAA-3'; RW 5'-GCTCACTGGGGTTAGCACAGA-3'), CXCL10 (FW 5'-CCTCATCCTGCTGGGTCTG-3'; RW 5'-CTCAACACGTGGGCAGGA-3'). All experiments were performed in triplicate and were normalized to glyceraldehyde 3-phosphate dehydrogenase (GAPDH) expression. The values of mRNA were calculated using the delta Ct method and expressed as change relative to the expression of GAPDH mRNA as an internal control.

\section{Irradiation and oral administration of metformin}

All animal procedures used in the present study were approved by the Yonsei University Health SystemInstitutional Animal Care and Use Committee (YUHS-IACUC; 2016-0199) and were performed in accordance with the relevant guidelines and regulations. C57BL/ 6 mice (age, 6 weeks; weight, 20-25 g) were purchased from Charles River Korea (Orient Bio, Seongnam, South Korea) and allowed to acclimatize ( $\mathrm{n}=5$ per cage) for a week before irradiation. Mice were anesthetized with an intraperitoneally administered mixture of $30 \mathrm{mg} / \mathrm{kg}$ Zoletil (tiletamine and zolazepam) and $10 \mathrm{mg} / \mathrm{kg}$ of Rompun (xylazine) and irradiated. Mouse irradiation and dosimetry were performed as previously described [27]. Briefly, radiation was delivered with an X-RAD 320 (Precision, North Branford, USA), equipped with fixed and adjustable collimation fixtures. The collimators produced a beam with a $1 \mathrm{~cm} \times 1 \mathrm{~cm}$ coverage area. The aluminum-filtered X-ray beam dose rate was $8.3 \mathrm{cGy} / \mathrm{s}$, measured at $320 \mathrm{kV}$ and $12.5 \mathrm{~mA}$ using a cylindrical ionization Farmertype chamber (PTW $0.6 \mathrm{~cm} 2$, waterproof) within an RW3 phantom at a source-to-surface distance of $2 \mathrm{~cm}$. Radiation dosimetry for cultured cells was carried out using a $60 \mathrm{~mm}$ dish, water, and RW3 phantom slab, and GAFCHROMIC EBT3 film. The cell culture dishes were filled with water. EBT3 film was placed in the 


\section{Cellular Physiology Cell Physiol Biochem 2018;48:959-970 \begin{tabular}{l|l} 
DOI: 10.1159/000491964 & $\begin{array}{l}\text { O 2018 The Author(s). Published by S. Karger AG, Basel } \\
\text { www.karger.com/cpb }\end{array}$
\end{tabular} \\ Kim et al.: Metformin Regulates Radiation-Induced Skin Fibrosis}

bottom of each dish for radiation dose assessment. In this experiment, cells were administered $10 \mathrm{~Gy}$ in one fraction.

Metformin was dissolved in distilled water, diluted with carboxymethylcellulose $(0.5 \% \mathrm{w} / \mathrm{v})$, and was orally administered in a single dose (50 or $100 \mathrm{mg} / \mathrm{kg}$ ) three times a week after a day of radiation exposure to a single 30 or $50 \mathrm{~Gy}$ fraction of radiation on the dorsal skin of mice. On the sixth week following irradiation, the mice were sacrificed, and the skin tissues were collected for further analyses

\section{Preparation of skin tissues and staining}

Skin tissues were fixed in a $4 \%$ paraformaldehyde solution and then embedded in paraffin. Sections of skin tissue, $4 \mu \mathrm{m}$ thick, were stained with hematoxylin and eosin (H\&E) and Masson's trichrome (SigmaAldrich, St. Louis, MO, USA) according to the manufacturers' instructions. As shown in Fig 1A (top), the histology of skin tissue shows epidermis, dermis and subcutaneous layer in order from top to bottom. For immunohistochemistry, skin tissues were incubated at $4^{\circ} \mathrm{C}$ overnight with an anti-FOXO3 or anti-8-OHdG (Abcam, Cambridge, MA, USA) primary antibody. After the tissue slides were incubated with avidin-biotin peroxidase complex (ABC kit, Vector Laboratories, Burlingame, CA, USA), the color was developed with 3, 3'-diaminobenzidine tetrachloride (DAB; Zymed Laboratories, CA, USA). After immunohistochemical staining, the slides were counterstained with Harris's hematoxylin for $1 \mathrm{~min}$ and then mounted with Canada balsam (Sigma-Aldrich, St. Louis, MO, USA). For immunofluorescence staining, skin tissues were incubated overnight with anti-SMA or anti-FOXO3 (Abcam, Cambridge, MA, USA) that were diluted in PBS containing $0.5 \%$ BSA and were subsequently incubated for 2 hours at room temperature with secondary fluorescentconjugated secondary antibodies that were diluted in PBS containing $0.5 \%$ BSA. And, these were mounted on gelatin-coated slide with fluorescent mounting medium (Dako, Glostrup, Denmark) and dried.

\section{Immunocytochemistry}

After culturing on coverslips coated with poly-L-lysine, the cells were fixed with 4\% paraformaldehyde in PBS and permeabilized with $0.1 \%$ Triton X-100 for 10 minutes at room temperature. After several washes with PBS, cell were incubated with the FOXO3 primary antibody at $4^{\circ} \mathrm{C}$ overnight, after blocking with $1 \%$ bovine serum albumin in PBS. Next, the cells were stained with a secondary antibody that was conjugated with Texas Red and subsequently stained with DAPI. The coverslips were then mounted and the fixed, stained cells were observed using a confocal fluorescence microscope.

\section{Statistical analysis}

The difference between the means of two study groups was evaluated by the Student's t-test. Differences between the means of multiple groups were evaluated by one-way analysis of variance (ANOVA) followed by Dunnett's multiple comparison test. The threshold for statistical significance was $\mathrm{p}<0.05$ for both tests. All values are expressed as the mean \pm SEM. Statistical significance was evaluated using the GraphPad Prism (GraphPad Software, La Jolla, CA, USA).

\section{Results}

\section{Radiation-induced skin damage}

In order to investigate the histologic changes and the deposition of collagen in the dorsal skin of mice irradiated with 30 Gy or 50 Gy X-rays in this study, hematoxylin and eosin (H\&E) staining and Masson's Trichrome (MT) staining were performed 6-weeks post-irradiation. Both dermal tissue enrichment and progressive collagen deposition were observed in the model of radiation-induced mouse skin fibrosis, as demonstrated in Figures 1A-B. In order to examine the effect of radiation on the gene expression of inflammatory mediators, we measured the expression levels of cytokines, including IL- 6 and TGF $\beta$, which play important roles during murine inflammatory responses. Using immunohistochemistry (Fig. 1C), we observed a significant increase in their expression in irradiated murine skin tissues compared with that in the control group. Additionally, the effect of irradiation on the expression of pro-inflammatory cytokines and chemokines was investigated by irradiating the cell lines of normal mouse fibroblasts (NIH3T3) and normal primary mouse dermal fibroblasts (MDF) 
in vitro. As shown in Fig. 1D, irradiation significantly increased the expression of various inflammatory cytokines and chemokines, such as IL-1b, IL-8, CCL2, CCL4, and CXCL10, as well as those of IL- 6 and TGF $\beta$ in both NIH3T3 and MDF cell lines.

As aforementioned, the models of radiation-induced mouse skin fibrosis develop dermal thickening, fibrosis, alopecia, and display the increased expression of inflammatory cytokines, all of which closely resemble the characteristics of human skin injuries resulting from radiotherapy. Therefore, these models may be ideal studying the effects of radiationinduced skin injury, especially at the histological and molecular level [28].

Fig. 1. Radiation-induced skin tissue damage. A) Representative images of skin tissues that were irradiated with 30 Gy or 50 Gy in mouse skin tissue, sampled at 6 weeks, and stained with H\&E or MT. Irradiated sections demonstrated marked thickening of epidermis and dermis (100×). B) Quantification of relative skin thickness and collagen contents. Data are expressed as mean \pm standard error $\left({ }^{* * *} \mathrm{P}<0.001,{ }^{*} \mathrm{P}<0.05\right.$ and ${ }^{* *} \mathrm{P}<0.01$, versus control; $\mathrm{n}=8$; con = control). C) Representative immunohistological image of skin tissues that were stained by antibody for IL-6 and TGF $\beta(100 \times)$.

D) Cytokine and chemokine gene expression in irradiated NIH3T3 and MDF cells $\left({ }^{* * *} \mathrm{P}<0.001,{ }^{*} \mathrm{P}<0.05\right.$ and ${ }^{* *} \mathrm{P}<0.01 ; \mathrm{n}=3$; con = control, $\mathrm{IR}=$ irradiated).

Fig. 2. Metformin inhibited radiation-induced fibrosis on mice skin tissue. Either 50 or 100 $\mathrm{mg} / \mathrm{kg}$ of metformin (Me) was administered orally to $\mathrm{C} 57 \mathrm{BL} / 6$ mice. The skin samples were obtained by punch biopsies on the sixth week following irradiation at a dose of 50 Gy. A) Representative images of skin tissues; irradiated group (IR) with 50 Gy were treated with metformin, sampled at 6 weeks, and stained with H\&E or MT. Irradiated sections demonstrated marked thickening of epidermis
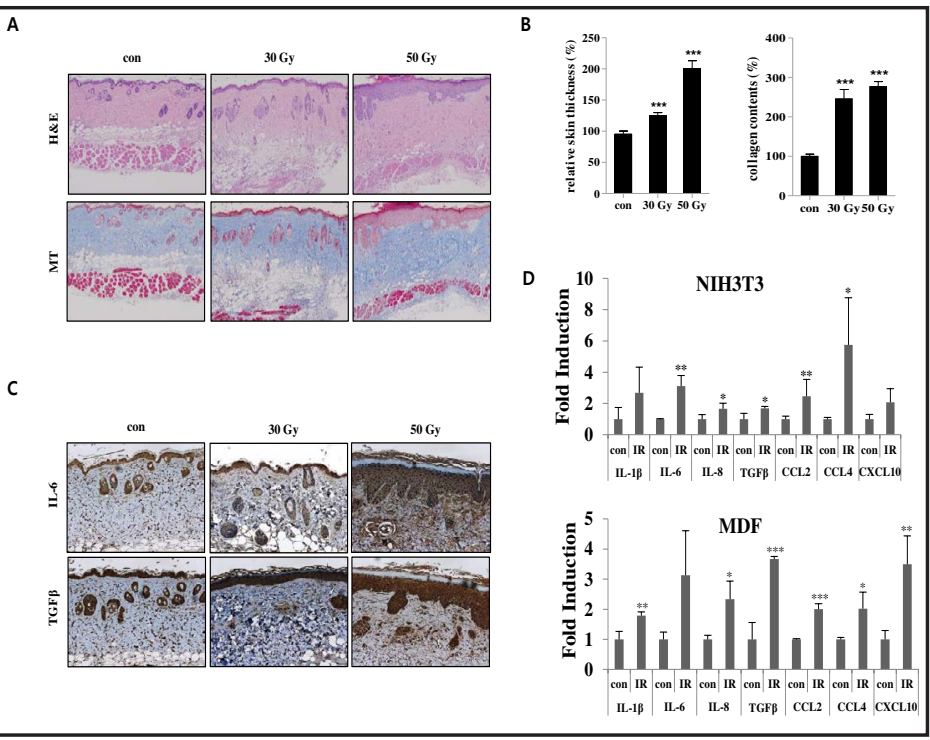

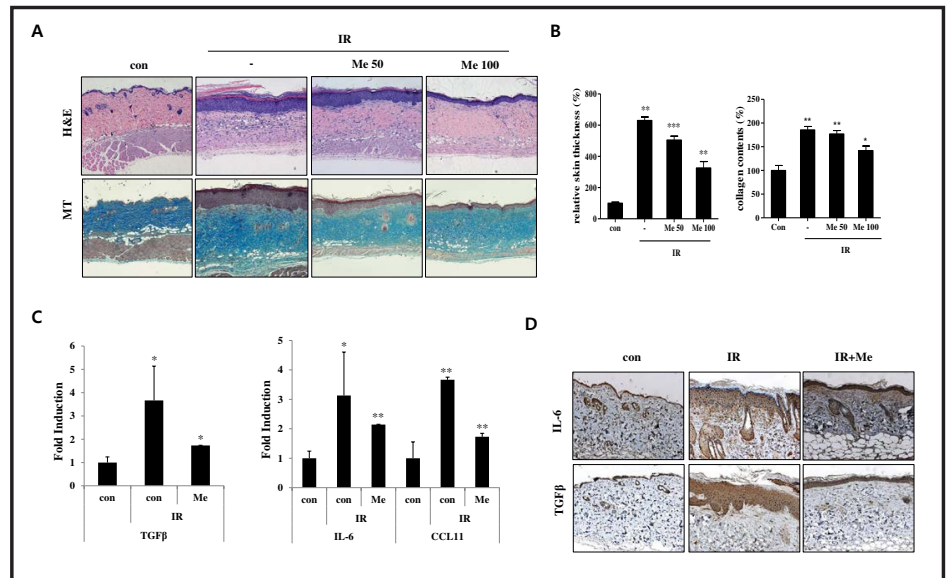

and dermis (100x). B) Quantification of relative skin thickness and collagen contents. C) mRNA expression of TGF $\beta$, IL-6, and CCL11 using real-time qPCR on skin tissue in mice. D) Representative immunohistological image of skin tissues, which were stained by antibody for IL- 6 and TGF $\beta$. Data are expressed as mean \pm standard error $\left({ }^{* * *} \mathrm{P}<0.001,{ }^{*} \mathrm{P}<0.05\right.$ and ${ }^{* *} \mathrm{P}<0.01 ; \mathrm{n}=3$; con $=$ control, $\mathrm{IR}=$ irradiated, $\mathrm{Me}=$ metformin). 


\section{Metformin inhibits irradiation-induced skin injury in mice}

Metformin was orally administered at doses of 50 or $100 \mathrm{mg} / \mathrm{kg}$, three times a week after irradiation, in models of radiation-induced mouse skin fibrosis, following which immunohistochemistry assays were performed. To evaluate whether metformin reduces dermal thickening and collagen synthesis in the skin, H\&E staining and MT staining were first performed using the tissues of the model of radiation-induced murine skin fibrosis. Following the administration of metformin, the thickness of the dermis, occurrence of hyperkeratosis, and the radiation-induced accumulation of collagen (Fig. 2A and 2B) were significantly reduced, while the mRNA (Fig. 2C) and protein (Fig. 2D) expression of radiationinduced inflammatory cytokines and chemokines, including TGF $\beta$, IL6, and chemokine 11 (CCL 11), were suppressed in the murine tissues. The irradiated NIH3T3 and MDF cells were subsequently treated with metformin, and analyzed by real-time qPCR and western blots, in order to confirm the in vitro effects of metformin. The protein levels of the pro-inflammatory cytokines TGF $\beta$ and IL-6, and CCL11, decreased in a dose-dependent manner, following treatment with metformin in the NIH3T3 cell lines (Fig. 3A). Also, the mRNA levels of TGF $\beta$, IL-6, and CCL11 decreased following the treatment of the MDF and NIH3T3 cell lines with metformin (Fig. 3B and 3C).

Fig. 3. Metformin reduced irradiationinduced cytokines and chemokine expression in vitro. NIH3T3 cells and MDF cells were treated with metformin (Me; 10 or $20 \mu \mathrm{M}$ ) for 30 minutes before irradiation (10 Gy). A) In NIH3T3 cells, protein expression of TGF $\beta$, IL-6, and CCL11 were evaluated with Western blot using antibody for TGF $\beta$, IL-6, and CCL11. B, C) mRNA expression of TGF $\beta$ (B), IL-6, and CCL11(C) in NIH3T3 cells and MDF cells, using quantitative real-time PCR. Data are expressed as mean \pm standard error $\left({ }^{* * *} \mathrm{P}<0.001,{ }^{*} \mathrm{P}<0.05\right.$ and ${ }^{* *} \mathrm{P}<0.01$; $\mathrm{n}=3$; con = control, $\mathrm{IR}=$ irradiated, $\mathrm{Me}=$

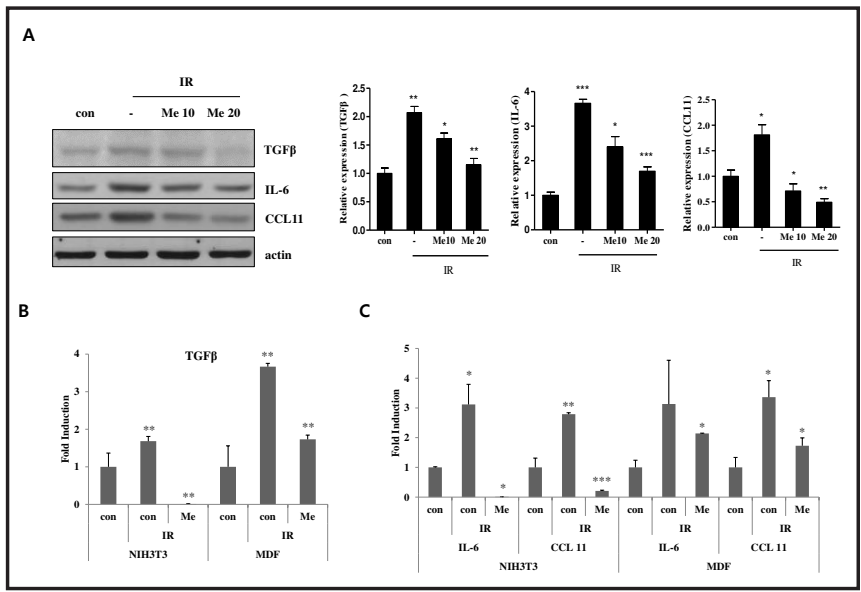
metformin).

Fig. 4. Metformin decreased radiationinduced STAT3 expression and oxidative stress. Metformin (Me) was orally administered at a dose of $100 \mathrm{mg} / \mathrm{kg}$ to C57BL/6 mice. The skin samples were obtained by punch biopsies on the sixth week following irradiation at a dose of 50 Gy. NIH3T3 were treated with metformin (Me; 10 or $20 \mu \mathrm{M}$ ) for 30 minutes before irradiation (10 Gy). Gene expressions in 10 Gy-irradiated cells at 1 hour and 4 hours, in NIH3T3. A) Representative immunohistological image of skin tissues

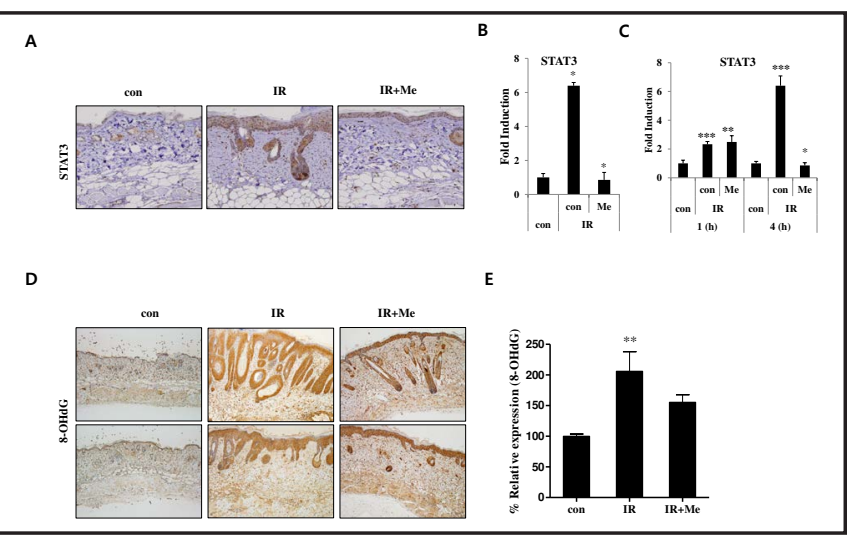
that were stained by anti-STAT3 $(100 \times)$.

B, C) mRNA expression of STAT3 was evaluated by quantitative real-time RT-PCR on skin tissue of mice (B) and in NIH3T3 cells (C). D) Representative immunohistological image of skin tissues that were stained by antibody for 8-OHdG (100×). E) Quantification of relative expression of 8-OHdG. Data are expressed as mean \pm standard error $\left({ }^{* * *} \mathrm{P}<0.001,{ }^{*} \mathrm{P}<0.05\right.$ and ${ }^{* *} \mathrm{P}<0.01, ; \mathrm{n}=3$; con $=$ control, $\mathrm{IR}=$ irradiated, $\mathrm{Me}=$ metformin $)$. 


\section{Cellular Physiology Cell Physiol Biochem 2018;48:959-970 \begin{tabular}{l|l} 
and Biochemistry Published onIIne: July 23, 2018 & $\begin{array}{l}\text { (c) } 2018 \text { The Author(s). Published by S. Karger AG, Basel } \\
\text { www.karger.com/cpb }\end{array}$
\end{tabular}

In addition, the expression levels of STAT3 mRNA and protein were reduced by metformin in models of radiation-induced murine skin fibrosis, as shown in Figures $4 \mathrm{~A}$ and 4B, respectively. Metformin also suppressed the expression of STAT3 that had been induced by radiation in vitro (Fig. 4C). And the radiation-induced expression of 8-OHdG, which served as a biomarker for oxidative stress [29], decreased in murine tissues following treatment with metformin (Fig. 4D and 4E).

Therefore, these results suggested that metformin significantly inhibits the proinflammatory response, and might attenuate radiation-induced skin fibrosis.

\section{Metformin regulates FOXO3 expression and suppresses radiation-induced fibrosis}

To determine whether the expression of FOXO3 during skin fibrosis could be regulated by metformin, we examined the effect of metformin on FOXO3 expression. Interestingly, metformin inhibited the radiation-induced expression of FOXO3 as revealed by the results of immunohistochemistry (Fig. 5A) and real-time qPCR (Fig. 5B). Additionally, metformin reduced the radiation-induced expression of nuclear FOXO3, which acts as a transcription factor (Fig. 5C). The expression of smooth muscle actin (SMA), a marker of fibrosis, was increased by irradiation; however, treatment with metformin suppressed its expression, as shown in Fig. 5D. Additionally, the expression of FOXO3 was merged with SMA in irradiated murine skin tissues (Fig. 5E), while siRNA-mediated silencing of the FOXO3 gene suppressed the radiation-induced expression of TGF $\beta$ (Fig. 5F). These results suggested that metformin alleviates radiation-induced skin fibrosis by downregulating FOXO3.

\section{FOXO3 regulates radiation-induced fibrosis via PIK3rl \\ This study additionally identified} that the expression of PIK3r1

Table 1. Sequencing results by GO pathway

\begin{tabular}{lll}
\hline Gene & Description & log2 Fold \\
\hline Mylk2 & myosin, light polypeptide kinase 2, skeletal muscle & -2.750052364 \\
Mylk4 & myosin light chain kinase family, member 4 & -5.159838576 \\
Ntrk2 & neurotrophic tyrosine kinase, receptor, type 2 & -2.547840837 \\
Pdk2 & pyruvate dehydrogenase kinase, isoenzyme 2 & -2.788946035 \\
Phkg1 & phosphorylase kinase gamma 1 & -2.766287995 \\
Pik3c2g phosphatidylinositol 3-kinase, C2 domain containing, gamma polypeptide & -1.927830068 \\
Pik3r1 & phosphatidylinositol 3-kinase, regulatory subunit, polypeptide 1 (p85 alpha) & -1.449235635 \\
Pke1 & phospholipase C, epsibn 1 & -2.004705134 \\
Ptpn14 & protein tyrosine phosphatase, non-receptor type 14 & -1.447858686 \\
Rorc & RAR-related orphan receptor gamma & -1.862459189 \\
Wnk2 & WNK lysine deficient protein kinase 2 & -1.470070694 \\
\hline
\end{tabular}

Fig. 5. Metformin alleviated radiation-induced fibrosis via F0X03. Metformin (Me) was orally administered at a dose of $100 \mathrm{mg} / \mathrm{kg}$ to $\mathrm{C} 57 \mathrm{BL} / 6$ mice. The skin samples were obtained by punch biopsies on the sixth week following irradiation at a dose of 50 Gy. NIH3T3 were treated with metformin (Me; 10 or $20 \mu \mathrm{M}$ ) before irradiation (10 Gy). A) Representative immunohistological image of skin tissues that were stained by anti-FOXO3 (100x). B) mRNA expression of FOXO3 was evaluated

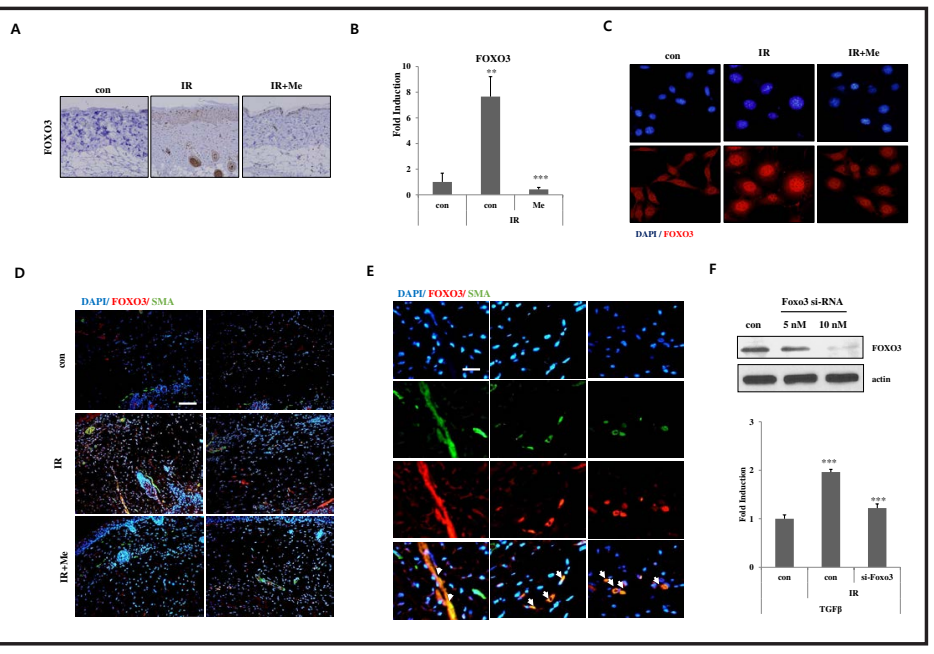
by quantitative real-time PCR on skin tissue in mice. C) NIH3T3 cells were stained with anti-FOXO3 (red). Blue indicates DAPI staining. D, E) Skin tissues were stained with anti-FOXO3 (red) and anti-SMA (green). Blue indicates DAPI staining. F) NIH3T3 cells were transfected with si-RNA for FOX03. Cells were lysed and lysates were analyzed for antiFOX03 by Western blotting, and then analyzed by real-time RT-qPCR for TGF $\beta$. Data are expressed as mean \pm standard error $\left({ }^{* * *} \mathrm{P}<0.001,{ }^{*} \mathrm{P}<0.05\right.$ and ${ }^{* *} \mathrm{P}<0.01 ; \mathrm{n}=3$; con $=$ control, $\mathrm{IR}=$ irradiated, $\mathrm{Me}=$ metformin $)$. 
Fig. 6. FOXO3 expression was regulated by PIK3r1 and p53. A, B) mRNA expression of PIK3r1 using quantitative real-time RT-PCR that were irradiated on skin tissue of mice (A), NIH3T3 and MDF cells (B). C) NIH3T3 cells were transfected with p85. Cells were analyzed by quantitative real-time RT-PCR for TGF $\beta$. D, E) $100 \mathrm{mg} / \mathrm{kg}$ of metformin (Me) was administered orally to C57BL/6 mice. PIK3rl expression was analyzed by quantitative real-time RT-PCR (D) and Western blotting (E). F) NIH3T3 were treated with metformin $(20 \mu \mathrm{M})$ before irradiation (10 Gy). PIK3rl expressions were analyzed by Western blotting. G) NIH3T3 cells were transfected with p85. F0X03 expression was analyzed by quantitative real-time RT-PCR. H-I) NIH3T3 were transfected with si-RNA for p53 before irradiation (5 or $10 \mathrm{~Gy}$ ). FOXO3 expressions were analyzed by Western blotting $(\mathrm{H})$ and

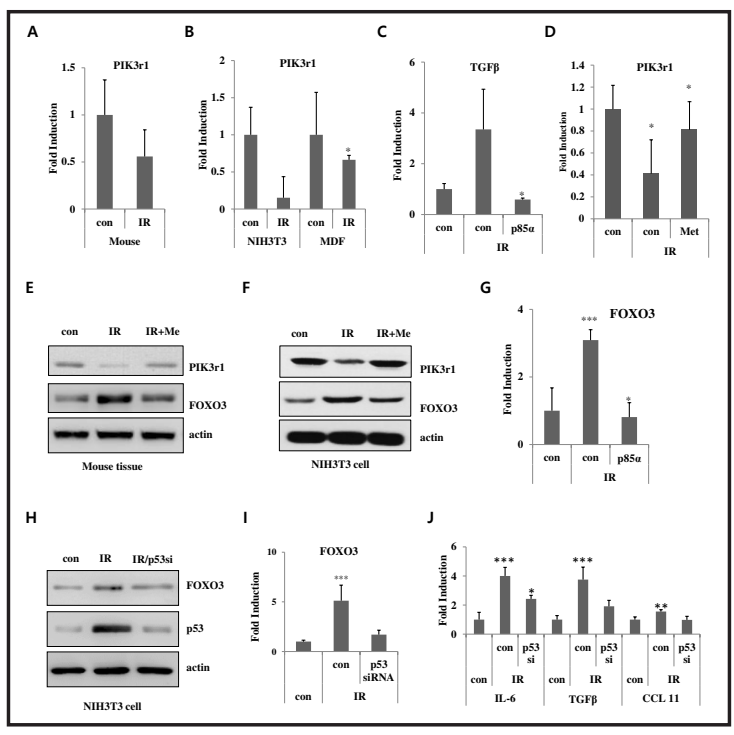
quantitative real-time RT-PCR (I). mRNA levels for IL-6, TGF $\beta$, and CCL11 (J) were analyzed by quantitative real-time RT-PCR. $\left({ }^{* * *} \mathrm{P}<0.001,{ }^{*} \mathrm{P}<0.05\right.$ and ${ }^{* *} \mathrm{P}<0.01 ; \mathrm{n}=3$; con = control, $\mathrm{IR}=$ irradiated, $\mathrm{Me}=$ metformin).

(phosphatidylinositol 3-kinase, regulatory subunit, polypeptide 1; p85 alpha), which is a subunit of PI3K and is involved in phosphate metabolism, was reduced, as revealed by analyses of the RNA-sequencing data (Table 1) in the model of radiation-induced skin fibrosis. The mRNA levels of PIK3r1 decreased in the irradiated murine dorsal skin tissues (Fig. 6A) and in irradiated NIH3T3 and MDF cell lines (Fig. 6B) compared with that in the control group, as revealed by real-time qPCR analyses. The overexpression of PIK3r1 in NIH3T3 cells decreased the expression of TGF $\beta$ that had been induced by irradiation (Fig. 6C).

Since PI3K plays an important role in the AMPK-FOXO3 axis [30], this study proceeded to investigate whether metformin could regulate the expression of PIK3r1 and FOXO3 for suppressing skin fibrosis. Interestingly, metformin enhanced the mRNA and protein levels of PI3Kr1 that had been suppressed by irradiation, as shown in Figures 6D and 6E, respectively. Similar findings were observed for the NIH3T3 cells (Fig. 6F). Additionally, the overexpression of PIK3r1 suppressed the radiation-induced expression of FOXO3 (Fig. 6G). p53 siRNA reduced radiation-induced F0X03 expression (Fig. 6H and 6I) and decreased the expression of cytokines, such as IL-6, TGF $\beta$, and CCL11 that had been induced irradiation (Fig. 6J).

Taken together, these results suggested that metformin enhances the expression of PIK3r1, which in turn suppresses FOXO3 expression, indicating that metformin may serve as an effective therapy in the treatment of radiation-induced skin injury.

\section{Discussion}

Radiotherapy can cause skin damage and result in either the loss or disruption of bone and soft tissue vasculature. Exposure of the skin to radiation results in a cascade of cellular events, leading to acute and chronic skin injuries. In our previous study, we also performed RNA sequencing using next-generation sequencing (NGS) technologies for examining the gene expression profiles in normal and irradiated murine skin tissues. After identifying 682 differentially expressed genes, we classified them using DESeq; the expression of 334 genes were found to increase, while those of 348 genes decreased following irradiation of the dorsal skin of mice, suggesting that the modulation of the pyruvate metabolic pathway via PDK2 suppresses radiation-induced skin injury in mice [27]. In this study, we identified 
that the expression of the subunits of PI3K, including PIKk3c2g (phosphatidylinositol 3-kinase, C2 domain containing, gamma polypeptide) and PIK3r1 (phosphatidylinositol 3-kinase, regulatory subunit, polypeptide 1; p85 alpha), decreases following irradiation, as demonstrated by the DESeq classification method and real-time qPCR (Table 1). In this study, we demonstrated that the expression of PIK3rl is suppressed after exposure to radiation, and metformin, which is an AMPK activator, inhibits radiation-induced skin fibrosis by regulating the expression of FOXO3 and the components functioning downstream of PIK3rl.

Skin fibrosis is treated by the application of steroid drugs, immunotherapy using antibodies, surgical therapy, among others [31]. However, the molecular pathogenesis of these conditions after radiation exposure remains to be elucidated. Metformin is a selective AMPK activator that inhibits the TGF $\beta$-signaling pathway mediated by the activation of AMPK during fibrosis, including cardiac fibrosis, cystic fibrosis, and gefitinib- or bleomycininduced pulmonary fibrosis [12, 32-37]. It also alleviates bleomycin-induced skin fibrosis $[32,38]$, and inhibits TGF $\beta$-induced collagen production in renal fibroblasts of mice [33]. However, the effect of metformin on radiation-induced fibrosis is not well-known. Several reports have shown that metformin inhibits FOXO3 activity $[39,40]$ while also playing an important role in the AMPK-FOXO3 axis [30,41]. Numerous studies have also suggested that metformin inhibits cardiac and renal fibrosis by regulating the TGF $\beta$ signaling pathway, which is important in fibrosis $[12,42]$. FOXO3, which is regulated by the AMPK signaling pathway [43, 44], has been found to be an important mediator of TGF $\beta$ gene expression [45]. Moreover, the PI3K-AKT signaling pathway negatively regulates the pro-apoptotic forkhead transcription factors (FOXO) $[16,17,19]$. Our data showed that metformin significantly reduces the thickness of the skin, the accumulation of collagen, and the expression of STAT3, cytokines, and chemokines, including TGF $\beta$, IL-6, and CCL 11, which are associated with inflammation and fibrosis during radiation exposure. Therefore, metformin might antagonize radiation-induced skin fibrosis in mice. Compared with normal cells, treatment with metformin markedly reduced the radiation-induced increase in cell size (Fig. 5C), which is a feature of senescent cells [46]. In addition, the onset of senescence in myofibroblasts has been found to control fibrogenesis by inducing the deposition of extracellular matrix (ECM) during wound healing [47]. We proceeded to examine whether PIK3r1 and FOXO3 could affect the pathology of irradiated skin. By analyzing with real-time qPCR, we confirmed that PIK3rl-transfected NIH3T3 cells had markedly reduced the expression of TGF $\beta$ and FOXO3, compared with that of the empty vector-transfected cells. Also, the siRNA-mediated silencing of FOXO3 attenuated the radiation-induced expression of TGF $\beta$. These data suggested that PIK3r1 downregulates the expression of FOXO3 and that both of them may regulate RIF. Taken together, we suggest that metformin suppressed the radiation-induced expression of FOXO3 via PIK3r1. However, future studies will need to address the mechanism by which metformin could affect the AMPK-FOXO3 axis during the RIF of skin.

Moreover, we additionally investigated whether p53 regulates RIF by regulating the expression of FOXO3. p53 functions downstream of PI3K/AKT [20] and is known to transactivate FOXO3 in fibroblasts by binding to the second intron of FOXO3 [26]. In this study, we evaluated whether p53 siRNA could inhibit the radiation-induced gene expression of cytokines and the expression of FOXO3. We transfected NIH3T3 cells with p53 siRNA and measured gene expression by real-time PCR. As expected, p53 siRNA significantly suppressed the radiation-induced gene expression of cytokines and the radiation-induced expression of FOXO3 (Fig. 6H-J). p53 has been shown to regulate cell fate determination in response to cellular stresses in many cell lines, and is known for its roles in programmed cell death. Recent studies have also demonstrated potential crosstalk between p53 and the transcription factor, FOXO3. Thus, FOXO3 may also modulate cell death and cell survival [48]. Therefore, the precise signaling mechanisms between p53 and FOXO3 that lead to radiationinduced skin damage need to be further investigated.

This study revealed that metformin suppresses radiation-induced skin fibrosis and outlined that the mechanism underlying this effect is mediated via the FOXO3 signaling pathway. This study is also the first to demonstrate that metformin prevents radiation- 


\section{Cellular Physiology Cell Physiol Biochem 2018;48:959-970

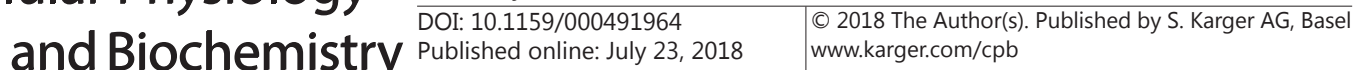

induced skin inflammation and fibrosis. Our findings further suggested that the therapeutic efficacy of metformin may be by its suppression of the expression of FOXO3 via PIK3r1, highlighting the potential use of metformin as a novel anti-fibrotic agent for the treatment of radiation-induced skin injuries.

\section{Acknowledgements}

This study was supported by a grant from the Korea Institute of Radiological and Medical Sciences (KIRAMS), funded by Ministry of Science ICT (MSIT), Republic of Korea (1711045557; 1711045538; 1711045554). The study was also funded by the Radiation Technology Research and Development Program (NRF-2017M2A2A7A02019612, 2015M2A2A7A03044831), and the Basic Science Research Program (NRF2016R1A6A3A11932226, 2017R1D1A1B03027881) through the National Research Foundation of Korea, funded by the Ministry of Education, by the Convergence of Conventional Medicine and Traditional Korean Medicine R\&D program funded by the Ministry of Health \& Welfare through the Korea Health Industry Development Institute (HI15C0214). Also, a faculty research grant from the Yonsei University College of Medicine (6-2016-0158) supported the study.

\section{Disclosure Statement}

The authors have no conflict of interests to declare.

\section{References}

1 Gieringer M, Gosepath J, Naim R: Radiotherapy and wound healing: principles, management and prospects (review). Oncol Rep 2011;26:299-307.

2 Hymes SR, Strom EA, Fife C: Radiation dermatitis: clinical presentation, pathophysiology, and treatment 2006. J Am Acad Dermatol 2006;54:28-46.

3 Hoppe BS, Laser B, Kowalski AV, Fontenla SC, Pena-Greenberg E, Yorke ED, Lovelock DM, Hunt MA, Rosenzweig KE: Acute skin toxicity following stereotactic body radiation therapy for stage I non-small-cell lung cancer: who's at risk? Int J Radiat Oncol Biol Phys 2008;72:1283-1286.

4 Hadad I, Johnstone BH, Brabham JG, Blanton MW, Rogers PI, Fellers C, Solomon JL, Merfeld-Clauss S, DesRosiers CM, Dynlacht JR, Coleman JJ, March KL: Development of a porcine delayed wound-healing model and its use in testing a novel cell-based therapy. Int J Radiat Oncol Biol Phys 2010;78:888-896.

5 Bray FN, Simmons BJ, Wolfson AH, Nouri K: Acute and Chronic Cutaneous Reactions to Ionizing Radiation Therapy. Dermatol Ther (Heidelb) 2016;6:185-206.

-6 Kim JH, Kolozsvary AJ, Jenrow KA, Brown SL: Mechanisms of radiation-induced skin injury and implications for future clinical trials. Int J Radiat Biol 2013;89:311-318.

7 Ryan JL: Ionizing radiation: the good, the bad, and the ugly. J Invest Dermatol 2012;132:985-993.

-8 Rodemann HP, Bamberg M: Cellular basis of radiation-induced fibrosis. Radiother Oncol 1995;35:83-90.

-9 Rubin P, Johnston CJ, Williams JP, McDonald S, Finkelstein JN: A perpetual cascade of cytokines postirradiation leads to pulmonary fibrosis. Int J Radiat Oncol Biol Phys 1995;33:99-109.

10 Delanian S, Baillet F, Huart J, Lefaix JL, Maulard C, Housset M: Successful treatment of radiation-induced fibrosis using liposomal Cu/Zn superoxide dismutase: clinical trial. Radiother Oncol 1994;32:12-20.

11 Yucel S, Sahin B, Gural Z, Olgac V, Aksu G, Agaoglu F, Saglam E, Aslay I, Darendeliler E: Impact of Superoxide Dismutase-Gliadin on Radiation-induced Fibrosis: An Experimental Study. In vivo 2016;30:451-456.

12 Foretz M, Guigas B, Bertrand L, Pollak M, Viollet B: Metformin: from mechanisms of action to therapies. Cell Metab 2014;20:953-966. 


\section{Cellular Physiology Cell Physiol Biochem 2018;48:959-970 \begin{tabular}{l|l} 
DOI: 10.1159/000491964 2018 & $\begin{array}{l}\text { O 2018 The Author(s). Published by S. Karger AG, Basel } \\
\text { www.karger.com/cpb }\end{array}$
\end{tabular}}

Kim et al.: Metformin Regulates Radiation-Induced Skin Fibrosis

13 Myerburg MM, King JD, Jr., Oyster NM, Fitch AC, Magill A, Baty CJ, Watkins SC, Kolls JK, Pilewski JM, Hallows KR: AMPK agonists ameliorate sodium and fluid transport and inflammation in cystic fibrosis airway epithelial cells. Am J Respir Cell Mol Biol 2010;42:676-684.

14 Kato M, Takahashi F, Sato T, Nurwidya F, Kobayashi I, Kanemaru R, Ko R, Yagishita S, Muraki K, Takahashi M, Shimada N, Yoshioka Y, Takahashi K: Metformin Inhibits Bleomycin-Induced Pulmonary Fibrosis In Mice. Am J Respir Crit Care Med 2014;189:1.

15 Wang J, Wang Y, Han J, Mei H, Yu D, Ding Q Zhang T, Wu G, Peng G, Lin Z: Metformin Attenuates RadiationInduced Pulmonary Fibrosis in a Murine Model. Radiat Res 2017;188:105-113.

16 Strozyk E, Kulms D: The role of AKT/mTOR pathway in stress response to UV-irradiation: implication in skin carcinogenesis by regulation of apoptosis, autophagy and senescence. Int J Mol Sci 2013;14:1526015285.

17 Calay D, Vind-Kezunovic D, Frankart A, Lambert S, Poumay Y, Gniadecki R: Inhibition of Akt signaling by exclusion from lipid rafts in normal and transformed epidermal keratinocytes. J Invest Dermatol 2010;130:1136-1145.

18 Vogt PK, Hart JR, Gymnopoulos M, Jiang H, Kang S, Bader AG, Zhao L, Denley A: Phosphatidylinositol 3-kinase: the oncoprotein. Curr Top Microbiol Immunol 2010;347:79-104.

19 Kim J, Choi H, Cho EG, Lee TR: FoxO3a is an antimelanogenic factor that mediates antioxidant-induced depigmentation. J Invest Dermatol 2014;134:1378-1388.

20 Manning BD, Cantley LC: AKT/PKB signaling: navigating downstream. Cell 2007;129:1261-1274.

21 Van Der Heide LP, Hoekman MF, Smidt MP: The ins and outs of FoxO shuttling: mechanisms of FoxO translocation and transcriptional regulation. Biochem J 2004;380:297-309.

-22 Zhang Y, Gan B, Liu D, Paik JH: FoxO family members in cancer. Cancer Biol Ther 2011;12:253-259.

-23 Tikhanovich I, Cox J, Weinman SA: Forkhead box class 0 transcription factors in liver function and disease. J Gastroenterol Hepatol 2013;28:S125-131.

24 Yoon HE, Kim SJ, Kim SJ, Chung S, Shin SJ: Tempol attenuates renal fibrosis in mice with unilateral ureteral obstruction: the role of PI3K-Akt-FoxO3a signaling. J Korean Med Sci 2014;29:230-237.

25 Lee JC, Espeli M, Anderson CA, Linterman MA, Pocock JM, Williams NJ, Roberts R, Viatte S, Fu B, Peshu N, Hien TT, Phu NH, Wesley E, Edwards C, Ahmad T, Mansfield JC, Gearry R, Dunstan S, Williams TN, Barton A, Vinuesa CG, Consortium UIG, Parkes M, Lyons PA, Smith KG: Human SNP links differential outcomes in inflammatory and infectious disease to a FOXO3-regulated pathway. Cell 2013;155:57-69.

-26 Renault VM, Thekkat PU, Hoang KL, White JL, Brady CA, Kenzelmann Broz D, Venturelli OS, Johnson TM, Oskoui PR, Xuan Z, Santo EE, Zhang MQ, Vogel H, Attardi LD, Brunet A: The pro-longevity gene FoxO3 is a direct target of the p53 tumor suppressor. Oncogene 2011;30:3207-3221.

27 Yoo H, Kang JW, Lee DW, Oh SH, Lee YS, Lee EJ, Cho J: Pyruvate metabolism: A therapeutic opportunity in radiation-induced skin injury. Biochem Biophys Res Commun 2015;460:504-510.

28 Kim JW, Lee DW, Choi WH, Jeon YR, Kim SH, Cho H, Lee EJ, Hong ZY, Lee WJ, Cho J: Development of a porcine skin injury model and characterization of the dose-dependent response to high-dose radiation. J Radiat Res 2013;54:823-831.

29 Valavanidis A, Vlachogianni T, Fiotakis C: 8-hydroxy-2' -deoxyguanosine (8-OHdG): A critical biomarker of oxidative stress and carcinogenesis. J Environ Sci Health C Environ Carcinog Ecotoxicol Rev 2009;27:120139.

-30 Carmignani M, Volpe AR, Aldea M, Soritau O, Irimie A, Florian IS, Tomuleasa C, Baritchii A, Petrushev B, Crisan G, Valle G: Glioblastoma stem cells: a new target for metformin and arsenic trioxide. J Biol Regul Homeost Agents 2014;28:1-15.

-31 Shaw TJ, Kishi K, Mori R: Wound-associated skin fibrosis: mechanisms and treatments based on modulating the inflammatory response. Endocr Metab Immune Disord Drug Targets 2010;10:320-330.

32 Choi SM, Jang AH, Kim H, Lee KH, Kim YW: Metformin Reduces Bleomycin-induced Pulmonary Fibrosis in Mice. J Korean Med Sci 2016;31:1419-1425.

33 Feng Y, Wang S, Zhang Y, Xiao H: Metformin attenuates renal fibrosis in both AMPKalpha2-dependent and independent manners. Clin Exp Pharmacol Physiol 2017;44:648-655.

-34 Ko MT, Huang HC, Lee WS, Chuang CL, Hsin IF, Hsu SJ, Lee FY, Chang CC, Lee SD: Metformin reduces intrahepatic fibrosis and intrapulmonary shunts in biliary cirrhotic rats. J Chin Med Assoc 2017;80:467475 . 


\section{Cellular Physiology Cell Physiol Biochem 2018;48:959-970 \begin{tabular}{l|l} 
DOI: 10.1159/000491964 2018 & $\begin{array}{l}\text { O } 2018 \text { The Author(s). Published by S. Karger AG, Basel } \\
\text { www.karger.com/cpb }\end{array}$ \\
\cline { 1 - 3 }
\end{tabular}

-35 Li L, Huang W, Li K, Zhang K, Lin C, Han R, Lu C, Wang Y, Chen H, Sun F, He Y: Metformin attenuates gefitinib-induced exacerbation of pulmonary fibrosis by inhibition of TGF-beta signaling pathway. Oncotarget 2015;6:43605-43619.

-36 Mummidi S, Das NA, Carpenter AJ, Kandikattu H, Krenz M, Siebenlist U, Valente AJ, Chandrasekar B: Metformin inhibits aldosterone-induced cardiac fibroblast activation, migration and proliferation in vitro, and reverses aldosterone+salt-induced cardiac fibrosis in vivo. J Mol Cell Cardiol 2016;98:95-102.

-37 Sato N, Takasaka N, Yoshida M, Tsubouchi K, Minagawa S, Araya J, Saito N, Fujita Y, Kurita Y, Kobayashi K, Ito S, Hara H, Kadota T, Yanagisawa H, Hashimoto M, Utsumi H, Wakui H, Kojima J, Numata T, Kaneko Y, Odaka M, Morikawa T, Nakayama K, Kohrogi H, Kuwano K: Metformin attenuates lung fibrosis development via NOX4 suppression. Respir Res 2016;17:107.

38 Ursini F, Grembiale RD, D’Antona L, Gallo E, D’Angelo S, Citraro R, Visca P, Olivieri I, De Sarro G, Perrotti N, Russo E: Oral Metformin Ameliorates Bleomycin-Induced Skin Fibrosis. J Invest Dermatol 2016;136:18921894.

-39 Sato A, Sunayama J, Okada M, Watanabe E, Seino S, Shibuya K, Suzuki K, Narita Y, Shibui S, Kayama T, Kitanaka C: Glioma-initiating cell elimination by metformin activation of FOXO3 via AMPK. Stem Cells Transl Med 2012;1:811-824.

40 Chiacchiera F, Simone C: The AMPK-FoxO3A axis as a target for cancer treatment. Cell Cycle 2010;9:10911096.

-41 Luo H, Yang Y, Duan J, Wu P, Jiang Q, Xu C: PTEN-regulated AKT/FoxO3a/Bim signaling contributes to reactive oxygen species-mediated apoptosis in selenite-treated colorectal cancer cells. Cell Death Dis 2013;4:e481.

42 Lu J, Shi J, Li M, Gui B, Fu R, Yao G, Duan Z, Lv Z, Yang Y, Chen Z, Jia L, Tian L: Activation of AMPK by metformin inhibits TGF-beta-induced collagen production in mouse renal fibroblasts. Life Sci 2015;127:5965.

43 Davila D, Connolly NM, Bonner H, Weisova P, Dussmann H, Concannon CG, Huber HJ, Prehn JH: Two-step activation of FOXO3 by AMPK generates a coherent feed-forward loop determining excitotoxic cell fate. Cell Death Differ 2012;19:1677-1688.

44 Ido Y, Duranton A, Lan F, Weikel KA, Breton L, Ruderman NB: Resveratrol prevents oxidative stress-induced senescence and proliferative dysfunction by activating the AMPK-FOXO3 cascade in cultured primary human keratinocytes. PLoS One 2015;10:e0115341.

45 Lee JC, Smith KG: Prognosis in autoimmune and infectious disease: new insights from genetics. Clin Transl Immunology 2014;3:e15.

46 Hayflick L: The Limited in vitro Lifetime of Human Diploid Cell Strains. Exp Cell Res 1965;37:614-636.

47 Jun JI, Lau LF: The matricellular protein CCN1 induces fibroblast senescence and restricts fibrosis in cutaneous wound healing. Nat Cell Biol 2010;12:676-685.

-48 You H, Mak TW: Crosstalk between p53 and FOXO transcription factors. Cell Cycle 2005;4:37-38. 